\title{
Stratocumulus Liquid Water Content from Dual-Wavelength Radar
}

\author{
Robin J. Hogan; Nicolas Gaussiat and Anthony J. Illingworth \\ Submitted to J. Atmos. Oceanic Technol., August 2004; Revised December 2004
}

\section{ABSTRACT}

\begin{abstract}
A technique is described to retrieve stratocumulus liquid water content (LWC) using the differential attenuation measured by vertically pointing radars at $35 \mathrm{GHz}$ and $94 \mathrm{GHz}$. Millimeter-wave attenuation is proportional to LWC and increases with frequency, so LWC can be derived without the need to make any assumptions on the nature of the droplet size distribution. There is also no need for the radars to be well calibrated. A significant advantage over many radar techniques in stratocumulus is that the presence of drizzle drops (those with a diameter larger than around $50 \mu \mathrm{m}$ ) does not affect the retrieval, even though such drops may dominate the radar signal. It is important, however, that there are not significant numbers of drops larger than $600 \mu \mathrm{m}$ which scatter outside the Rayleigh regime at $94 \mathrm{GHz}$. We use a lidar ceilometer to locate cloud base in the presence of drizzle falling below the cloud. An accuracy of around $0.04 \mathrm{~g} \mathrm{~m}^{-3}$ is achievable with averaging over one minute and 150 $\mathrm{m}$ (two range gates), but for the previously suggested frequency pair $10 \mathrm{GHz}$ and $35 \mathrm{GHz}$, the corresponding accuracy would be considerably worse at $0.34 \mathrm{~g} \mathrm{~m}^{-3}$. We first simulate the retrieval of LWC using aircraft-measured size spectra taken from a profile through marine stratocumulus. Results are then presented from two case studies, one using two cloud radars at Chilbolton in Southern England, and another using the Cloud Profiling Radar System at the Atmospheric Radiation Measurement site in Oklahoma. Liquid water path from the technique was found to be in good agreement with the values obtained from microwave radiometers, with the difference between the two being close to the accuracy of the radiometer retrieval. In the case of wellmixed stratocumulus the profiles were close to adiabatic.
\end{abstract}

\section{Introduction}

Of all clouds, low-level stratus and stratocumulus are the most important in the earth's radiation budget because they are both optically thick and have a large global coverage. By reflecting most of the incoming solar radiation back to space and yet emitting in the longwave at a similar brightness temperature to the surface, they have a cooling effect on climate (Randall et al. 1984; Slingo 1990).

The potential of cloud radar to measure stratocumulus has been recognised, and algorithms have been developed that utilize a microwave radiometer to measure the integrated water content of the column, which is then partitioned with height according to the radar reflectivity profile (Frisch et al. 1998). The main difficulty with this approach is that stratocumulus clouds often contain small concentrations of 'drizzle' drops (those larger than around $50 \mu \mathrm{m}$ ) that can dominate the radar reflectivity yet contribute negligibly to LWC. Fox and Illingworth (1997) found them to be ubiquitous in the large majority of the marine stratocumulus sampled during the Atlantic Stratocumulus Transition Experiment (ASTEX). Drizzle is also common in continental stratocumulus and limits the applicability of single-radar techniques to retrieve LWC and effective radius.

A useful property of liquid droplets is that, provided they are small enough to attenuate in the Rayleigh regime, their attenuation of microwave radiation is exactly proportional to LWC and increases with frequency. It is simple

${ }^{*}$ Corresponding author address: Department of Meteorology, Earley Gate, PO Box 243, Reading RG6 6BB, United Kingdom. E-mail: r.j.hogan@ reading.ac.uk. in principle, therefore, to use the difference in the reflectivity factor measured at two different wavelengths to deduce LWC, without the need to resort to any empirical relationships. A further advantage is that the method is insensitive to the absolute calibration of the radars; only the ability to measure differences in reflectivity is required. The use of differential attenuation to measure LWC was first suggested by Atlas (1954), and was originally envisioned for measuring the water content of rain. Eccles and Mueller (1971) proposed the use of 3- and 10-GHz radars to estimate LWC in convective storms, but in practice it was found that attenuation was only measurable over relatively long paths, and often the drops contributing most to the attenuation in heavy rain were large enough that the Rayleigh approximation was no longer applicable and attenuation was not proportional to LWC. Moreover, it is generally rain rate that is of interest operationally, so an empirical relationship had to be applied to relate LWC to rain rate. By contrast, in the study of low clouds, LWC is the parameter of interest, and the droplets contributing most to the attenuation (i.e. those containing the bulk of the liquid water) are invariably no more than $50 \mu \mathrm{m}$ in diameter (Miles et al. 2000), so even at $94 \mathrm{GHz}$ are two orders of magnitude smaller than the wavelength and firmly in the Rayleigh regime.

Martner et al. (1993) reported measurements of LWC from horizontal scans of a dual-wavelength radar at $10 \mathrm{GHz}$ and $35 \mathrm{GHz}$, but the two-way differential attenuation per $\mathrm{g} \mathrm{m}^{-3}$ of liquid water at $10^{\circ} \mathrm{C}$ is only $1.5 \mathrm{~dB} \mathrm{~km}^{-1}$ at these frequencies, and was measurable only at a resolution of $4 \mathrm{~km}$ or worse. Vivekanandan et al. (1999, 2001) used the same two frequencies to derive LWC in 
supercooled clouds from dwells at an elevation of $1.5^{\circ}$ but found that it was necessary to average over a range of $750 \mathrm{~m}$ (10 gates) and average for at least $30 \mathrm{~s}$ to reduce the random error sufficiently. In this paper we use 35and $94-\mathrm{GHz}$ radars, for which the differential attenuation becomes $7.1 \mathrm{~dB} \mathrm{~km}^{-1}\left(\mathrm{~g} \mathrm{~m}^{-3}\right)^{-1}$. This is clearly measurable even for vertically pointing instruments, and with sufficient temporal averaging the vertical profile of LWC in stratocumulus can be obtained.

In section 2 the mathematical basis of the algorithm is developed and in section 3 the likely accuracy is determined. In section 4, aircraft-measured droplet size spectra in stratocumulus are used to simulate the retrieval. The algorithm is then applied to real data in section 5, and compared with the liquid water path (LWP) both retrieved by microwave radiometers and calculated assuming an adiabatic profile.

\section{Theory}

In conventional logarithmic units the reflectivity measured at frequency $f$ and height $h$ may be given by

$Z_{f}=Z_{0}+10 \log _{10}\left(\frac{\left|K_{f}(T)\right|^{2}}{0.93}\right)-2 \int_{0}^{z}\left(\alpha_{f}+\kappa_{f}\right.$ LWC $) d h$

where $Z_{0}$ is the unattenuated reflectivity factor at centimeter wavelengths in $\mathrm{dBZ}$ units, $\alpha_{f}$ is the one-way specific attenuation coefficient due to atmospheric gases (predominantly molecular oxygen and water vapor) in $\mathrm{dB} \mathrm{km}^{-1}$, and $\kappa_{f}$ is the one-way specific attenuation coefficient of liquid water and has the units $\mathrm{dB} \mathrm{km}^{-1}\left(\mathrm{~g} \mathrm{~m}^{-3}\right)^{-1}$. The second term on the right hand side accounts for the fact that at millimeter wavelengths the dielectric factor of water, $|K|^{2}$, is less than its centimeter-wavelength value of 0.93 , and is a function of temperature. $K$ is related to the complex dielectric constant, $\varepsilon$, by $K=(\varepsilon-1) /(\varepsilon+2)$. In the Rayleigh approximation the attenuation coefficient of liquid water is given by (Doviak and Zrnić 1993)

$$
\kappa_{f}=4.343 \times 10^{3} \frac{6 \pi}{\lambda \rho_{1}} \operatorname{Im}(-K),
$$

where $\lambda$ is the radar wavelength, $\rho_{1}$ is the density of liquid water and Im denotes the imaginary part. We have assumed that extinction by absorption dominates extinction by scattering, which is a good assumption for low-level liquid water clouds.

We define the dual-wavelength ratio in logarithmic units as DWR $[\mathrm{dB}]=Z_{35}[\mathrm{dBZ}]-Z_{94}[\mathrm{dBZ}]$. From (1), the mean LWC in a layer between heights $h_{1}$ and $h_{2}$ can then be determined from the DWR measured at the top and bottom of the layer (indicated by the subscripts 2 and 1 respectively):

$\overline{\mathrm{LWC}}=\frac{1}{\kappa_{94}-\kappa_{35}}\left(\frac{\mathrm{DWR}_{2}-\mathrm{DWR}_{1}-\beta}{2\left(h_{2}-h_{1}\right)}-\alpha_{94}+\alpha_{35}\right)$, where

$$
\beta=10 \log _{10}\left(\frac{\left|K_{35}\left(T_{2}\right)\right|^{2}}{\left|K_{35}\left(T_{1}\right)\right|^{2}} \frac{\left|K_{94}\left(T_{1}\right)\right|^{2}}{\left|K_{94}\left(T_{2}\right)\right|^{2}}\right) \quad \mathrm{dB} .
$$

It has been assumed that the attenuation coefficients $\alpha$ and $\kappa$ are constant over the depth of the layer. The $\beta$ parameter is a small adjustment that accounts for the difference in temperature at the two heights.

The attenuation coefficients and the $\beta$ parameter are functions of temperature, and the attenuation of atmospheric gases is also dependent on pressure and humidity, so an independent measure of the vertical profiles of these variables is required in the retrieval. This can be obtained from radiosonde or from the output of a forecast model, although in practice it is always assumed that cloudy air is saturated with respect to liquid water. The sensitivity of the retrieval to errors in temperature is investigated in section $3 b$. We calculate $\varepsilon$ (and hence $\beta$ and $\kappa$ ) from temperature using the formulation of Liebe et al. (1989), and compute $\alpha_{f}$ as a function of temperature, pressure and humidity using the line-by-line model of Liebe (1985).

\section{Error estimates}

In this section the likely error in the technique is estimated. The accuracy to which LWC can be determined depends on the precision of the reflectivity measurements, the accuracy of the temperature profile and the validity of the Rayleigh scattering assumption. A further consideration is the overlap of the sample volumes of the radars; if the two instruments are separated or if their beamwidths are different then errors can arise due to cloud inhomogeneity. This effect is difficult to quantify as one must characterise the variability of the cloud as a function of scale, but it is alleviated by the temporal averaging described in section 3a. The fact that good results are obtained in section 5 using real data with imperfectly matched radar sample volumes indicates that, provided the radars are mounted close to each other, this effect is small.

\section{a. The effect of random errors in reflectivity factor}

It can be seen from (3) that the retrieval of LWC is insensitive to systematic (i.e. calibration) errors in $Z_{35}$ or $Z_{94}$, whereas random errors can affect the results. Assuming errors in $Z_{35}$ and $Z_{94}\left(\Delta Z_{35}\right.$ and $\left.\Delta Z_{94}\right)$ to be independent, the error in each dual-wavelength ratio, $\triangle \mathrm{DWR}$, is $\left(\Delta Z_{35}{ }^{2}+\Delta Z_{94}{ }^{2}\right)^{\frac{1}{2}}$. Hence, using (3), the error in LWC is directly related to the uncertainty in reflectivities:

$$
\Delta \mathrm{LWC}=\frac{\left(\Delta Z_{35}{ }^{2}+\Delta Z_{94}{ }^{2}\right)^{\frac{1}{2}}}{\sqrt{2}\left(\kappa_{94}-\kappa_{35}\right)\left(h_{2}-h_{1}\right)} .
$$

In the appendix it is shown that the precision in reflectivity (in dB) after averaging over $M$ pulses in time and $N$ range 


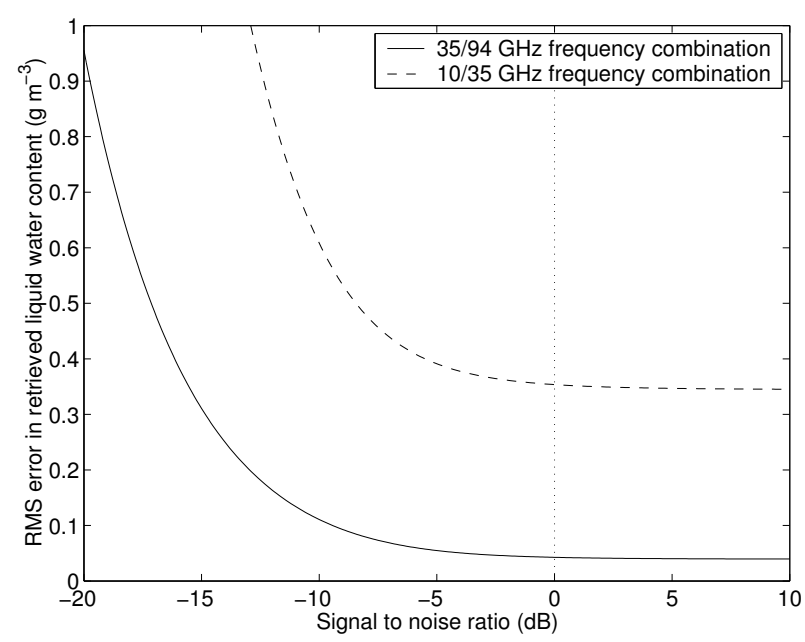

FIG. 1: The errors in retrieved LWC using the 10/35-GHz and the 35/94$\mathrm{GHz}$ radar frequency pairs versus signal-to-noise ratio for a $150-\mathrm{m}$ vertical resolution (2 gates), a 1-minute dwell, $T=10^{\circ} \mathrm{C}, \sigma_{w}=0.3 \mathrm{~m} \mathrm{~s}^{-1}$ and a pulse repetition frequency of $6250 \mathrm{~Hz}$ at both frequencies.

gates may be given by

$$
\Delta Z_{\mathrm{dB}}=\frac{4.343}{\sqrt{M N}}\left(\frac{\lambda}{4 \pi^{\frac{1}{2}} \sigma_{w} \tau_{\mathrm{s}}}+\frac{1}{\mathrm{SNR}^{2}}+\frac{2}{\mathrm{SNR}}\right)^{\frac{1}{2}},
$$

where $\lambda$ is the radar wavelength, SNR is the linear signalto-noise ratio, $\tau_{\mathrm{s}}$ is the time between pulses (i.e. the reciprocal of the pulse repetition frequency) and $\sigma_{w}$ is the spectral width, defined as the standard deviation of the reflectivity-weighted droplet vertical velocities in the radar pulse volume.

If we temporarily consider the case where the radars are equally sensitive and operate with the same pulse repetition frequency, then by combining (5) and (6), and recognising that $h_{2}-h_{1}=N \delta$ (where $\delta$ is the range gate spacing), we obtain

$$
\begin{aligned}
\Delta \mathrm{LWC}= & \frac{4.343}{\sqrt{2 M N^{3}}\left(\kappa_{94}-\kappa_{35}\right) \delta} \\
& \times\left(\frac{\lambda_{35}+\lambda_{94}}{4 \pi^{\frac{1}{2}} \sigma_{w} \tau_{\mathrm{s}}}+\frac{2}{\mathrm{SNR}^{2}}+\frac{4}{\mathrm{SNR}}\right)^{\frac{1}{2}} .
\end{aligned}
$$

With typical values of $\sigma_{w}=0.3 \mathrm{~m} \mathrm{~s}^{-1}$ (implying 150 independent pulses per second at $35 \mathrm{GHz}$ and 400 at $94 \mathrm{GHz}), \delta=75 \mathrm{~m}, T=10^{\circ} \mathrm{C}$ and $\mathrm{SNR} \gg 1$, we find that to retrieve LWC to an accuracy of $0.04 \mathrm{~g} \mathrm{~m}^{-3}$ with no vertical averaging requires a dwell time of nearly 8 minutes. However, if two gates are averaged in the vertical then the dwell time required to reach this accuracy drops to 1 minute. In practice a 2-gate sliding window is used to yield an LWC field with this accuracy but at the same vertical resolution as the original data. It should be noted that stratocumulus can have very low values of $Z$, which (depending on the radar sensitivity) can correspond

\begin{tabular}{cccc}
\hline LWC & \multicolumn{3}{c}{ Temperature } \\
$\left(\mathrm{g} \mathrm{m}^{-3}\right)$ & $0{ }^{\circ} \mathrm{C}$ & $10^{\circ} \mathrm{C}$ & $20^{\circ} \mathrm{C}$ \\
\hline 0.05 & -0.0041 & -0.0088 & -0.0242 \\
0.5 & -0.0054 & -0.0050 & -0.0187 \\
\hline
\end{tabular}

TABLE 1: Error in retrieved liquid water content $\left(\mathrm{g} \mathrm{m}^{-3}\right)$ associated with a $1^{\circ} \mathrm{C}$ error in temperature. A pressure of $1013 \mathrm{hPa}$ and a lapse rate of $-6^{\circ} \mathrm{C} \mathrm{km}^{-1}$ have been assumed.

to low values of SNR, and Fig. 1 shows the increase in error when $\mathrm{SNR}<1$ (0 dB in logarithmic units). This has been calculated assuming $\tau_{\mathrm{s}}=0.16 \mathrm{~ms}$ for both radars, equivalent to a pulse repetition frequency of $6250 \mathrm{~Hz}$.

Figure 1 also shows that substitution of the appropriate values of wavelength and differential attenuation in (7) for the alternative frequency combination of $10 \mathrm{GHz}$ and $35 \mathrm{GHz}$ leads to an eightfold increase in $\triangle \mathrm{LWC}$ to $0.34 \mathrm{~g} \mathrm{~m}^{-3}$ for a 1 -minute dwell and $150-\mathrm{m}$ resolution (2 gates). We conclude that it is not practical to derive vertical profiles of LWC with this frequency pair, although at low elevations, with averaging over $750 \mathrm{~m}$ and $30 \mathrm{~s}$, Vivekanandan et al. (1999) were able to achieve satisfactory results. Indeed, assuming high SNR we calculate that this would yield a theoretical accuracy of retrieved LWC of $0.04 \mathrm{~g} \mathrm{~m}^{-3}$.

\section{b. The effect of errors in temperature}

Naturally there will be errors in the temperature, humidity and pressure profiles used in the retrieval. It is reasonable to assume that the air will be very close to saturation whenever there is stratocumulus present, and pressure only affects the gaseous attenuation coefficients via the pressure broadening of the spectral absorption lines, so the principal error in the thermodynamic profile stems from errors in temperature. By differentiating (3) with respect to temperature $(T)$, we obtain an expression for the systematic error in LWC associated with an error in temperature of $\Delta T$ :

$$
\begin{aligned}
& \Delta \mathrm{LWC}=-\frac{\Delta T}{\kappa_{94}-\kappa_{35}}\left[\frac{d\left(\alpha_{94}-\alpha_{35}\right)}{d T}\right. \\
& \left.\quad+\mathrm{LWC} \frac{d\left(\kappa_{94}-\kappa_{35}\right)}{d T}+\frac{\Gamma}{2} \frac{d^{2}}{d T^{2}}\left(10 \log _{10} \frac{\left|K_{35}\right|^{2}}{\left|K_{94}\right|^{2}}\right)\right]
\end{aligned}
$$

where $\Gamma$ is the lapse rate. Note that the derivatives with temperature are at a constant relative humidity of $100 \%$. The largest error associated with an overestimate of temperature stems from the consequent overestimate of the specific humidity and its contribution to the differential attenuation, which in turn leads to an underestimate in LWC. This effect is represented by the first term in the square brackets of (8). The retrieval errors associated with a $1^{\circ} \mathrm{C}$ error in temperature are given in Table 1 for different values of $T$ and LWC. The error increases with temperature due to the exponential increase in saturation 
specific humidity with temperature, but even at $20^{\circ} \mathrm{C}$, the effect of a $4^{\circ} \mathrm{C}$ error on retrieved LWC would be less than $0.1 \mathrm{~g} \mathrm{~m}^{-1}$. We would expect the temperature to be known to better than $2^{\circ} \mathrm{C}$, so in general the errors should be acceptably low and typically smaller than those due to errors in $Z$.

\section{c. The effect of Mie scattering drizzle drops}

Errors in the retrieval technique can arise as a result of the Rayleigh scattering assumption not being valid. Figure 2 a shows the dual-wavelength ratio calculated using Mie theory for both individual spherical drops and for an inverse-exponential size distribution, known to be reasonable for representing drizzle (Ichimura et al. 1980; Wood 2000). Even though the cloud can be considered to be attenuating in the Rayleigh regime (because it is the very small cloud droplets that contain the bulk of the liquid water and are therefore responsible for the attenuation), it can be seen that the presence of significant numbers of drops larger than around $600 \mu \mathrm{m}$ would drastically reduce $Z_{94}$ below $Z_{35}$. If this were to result in a change in $\triangle \mathrm{DWR}$ greater than $0.1 \mathrm{~dB}$ in the space of one gate, then according to (5) this would bias the retrieved LWC by 0.05 $\mathrm{g} \mathrm{m}^{-3}$. Such drops are present in inverse-exponential distributions with a median equivolumetric diameter greater than around $300 \mu \mathrm{m}$. Note that small negative values of DWR are possible at smaller sizes due to a resonance effect at $94 \mathrm{GHz}$ (e.g. van de Hulst 1957) that increases with temperature.

Mie scattering can be identified unambiguously using three wavelengths (Gaussiat et al. 2003), but the Doppler velocities measured at two wavelengths provide equivalent information. The mean Doppler velocity for spherical drops and inverse exponential spectra is plotted in Fig. 2b and shows that provided the velocity is below $2.5 \mathrm{~m} \mathrm{~s}^{-1}$ the error in DWR should be less than $0.1 \mathrm{~dB}$. The mean Doppler velocity can be affected by vertical air motions, so a better approach is to use the difference in Doppler velocities at $35 \mathrm{GHz}$ and $94 \mathrm{GHz}$; Fig. 2c shows that once this exceeds $0.1 \mathrm{~m} \mathrm{~s}^{-1}$ there is a significant Mie scattering effect on DWR.

It should be stressed that it is the gradient with height of the departure from Rayleigh scattering that leads to erroneous LWC values. Hence, if a certain region of the cloud contains Mie scattering drops but the regions above and below are Rayleigh scattering, then the LWC errors at the top and bottom of the Mie-scattering region will be equal and opposite such that LWP is unaffected.

\section{d. The effect of the presence of ice particles}

The dual-wavelength attenuation technique at $35 \mathrm{GHz}$ and $94 \mathrm{GHz}$ is likely to experience severe difficulties in mixed-phase clouds, as the ice particles will grow rapidly in the supersaturated environment and scatter well outside the Rayleigh regime at $94 \mathrm{GHz}$. Previous research investigating the potential of dual-wavelength radar for mixed-phase clouds (e.g. Gosset and Sauvageot 1992, Vivekanandan et al. 1999) considered the wavelength combination of $10 \mathrm{GHz}$ and $35 \mathrm{GHz}$, thereby reducing the effect of non-Rayleigh scattering at the highest frequency. However, the differential attenuation for a given liquid water path is reduced by nearly a factor of five compared to the $35 \mathrm{GHz}$ and $94 \mathrm{GHz}$ combination, and the 35$\mathrm{GHz}$ measurements were still sometimes contaminated by non-Rayleigh scattering. Hence reliable results in mixedphase clouds are only likely with the addition of a third wavelength (Gaussiat et al. 2003).

We therefore restrict application of the $35 \mathrm{GHz}$ and $94 \mathrm{GHz}$ attenuation technique to purely liquid-phase clouds. As with Mie-scattering drizzle, the difference in Doppler velocity can be used to identify the presence of large non-Rayleigh scattering ice particles, but one could also identify and exclude clouds that might be affected simply on the basis of the temperature at cloud top.

\section{Simulation using aircraft data}

In this section the retrieval of LWC using vertically pointing dual-wavelength radar is simulated using a profile of the UK Met Office C-130 aircraft through stratocumulus from flight A209 of ASTEX (12 June 1992). The cloud was around $1.5 \mathrm{~km}$ thick, and in the $4.2 \mathrm{~min}-$ utes the aircraft took to descend through the cloud it travelled horizontally around $25 \mathrm{~km}$. The size distribution was measured by the Forward Scattering Spectrometer Probe and the 2D cloud probe, which together measure droplets ranging in diameter from 6.5 to $800 \mu \mathrm{m}$.

Figure 3 a shows the vertical profile of the liquid water spectral density, in which it can be seen that the bulk of the liquid water is contained in the droplets smaller than around $30 \mu \mathrm{m}$ in diameter, but drizzle drops up to $500 \mu \mathrm{m}$ are also present. The Doppler spectral width $\sigma_{w}$ due to the differential fall speed of the droplets was around $0.3 \mathrm{~m} \mathrm{~s}^{-1}$ through most of the depth of the cloud, but increased to $0.4 \mathrm{~m} \mathrm{~s}^{-1}$ below $500 \mathrm{~m}$ where the size distribution was bimodal. Figure $3 \mathrm{~b}$ shows the attenuated backscatter coefficient that would be measured by a ground based lidar, together with the corresponding unattenuated profile, calculated from the aircraft data assuming geometric optics and an extinction-to-backscatter ratio of 18 sr (Pinnick et al. 1983). The rapid attenuation of the lidar signal due to cloud droplets enables cloud base to be estimated easily from the attenuated backscatter profile even in the presence of drizzle; in this case it would be diagnosed at around $700 \mathrm{~m}$. Figure $3 \mathrm{c}$ shows the radar reflectivity factors at $35 \mathrm{GHz}$ and $94 \mathrm{GHz}$, accounting for Mie scattering and attenuation. Gaseous attenuation has been simulated by assuming a surface temperature of $10^{\circ} \mathrm{C}$, a lapse rate of $-6^{\circ} \mathrm{C} \mathrm{km}^{-1}$, and a relative humidity of $50 \%$ below $700 \mathrm{~m}$ and $100 \%$ above. Radar reflectivity is dominated by the contribution of the drizzle drops producing a large echo 

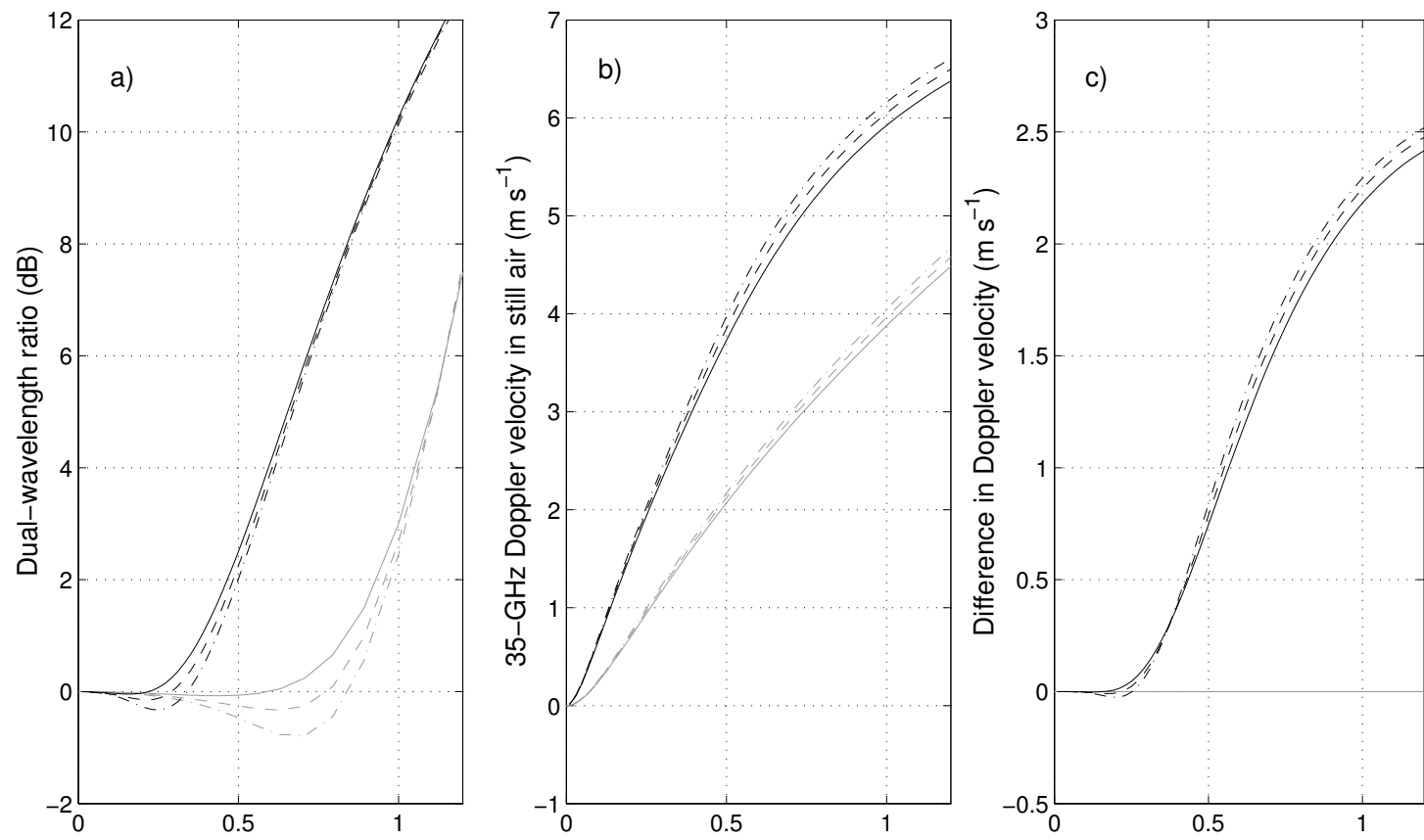

Median equivolumetric diameter $(\mathrm{mm})$

Median equivolumetric diameter $(\mathrm{mm})$

Median equivolumetric diameter $(\mathrm{mm})$
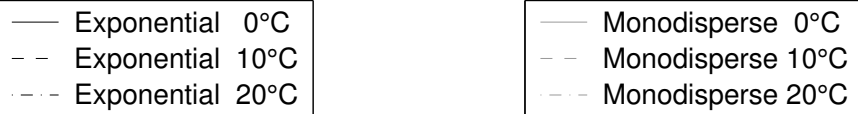

FIG. 2: (a) Dual-wavelength ratio, (b) mean Doppler velocity at $35 \mathrm{GHz}$, and (c) the difference in the mean Doppler velocity at $35 \mathrm{GHz}$ and $94 \mathrm{GHz}$, versus median equivolumetric diameter, for an inverse-exponential distribution of liquid water droplets (black lines) and a monodisperse distribution (gray lines) at temperatures of $0^{\circ} \mathrm{C}, 10^{\circ} \mathrm{C}$ and $20^{\circ} \mathrm{C}$.
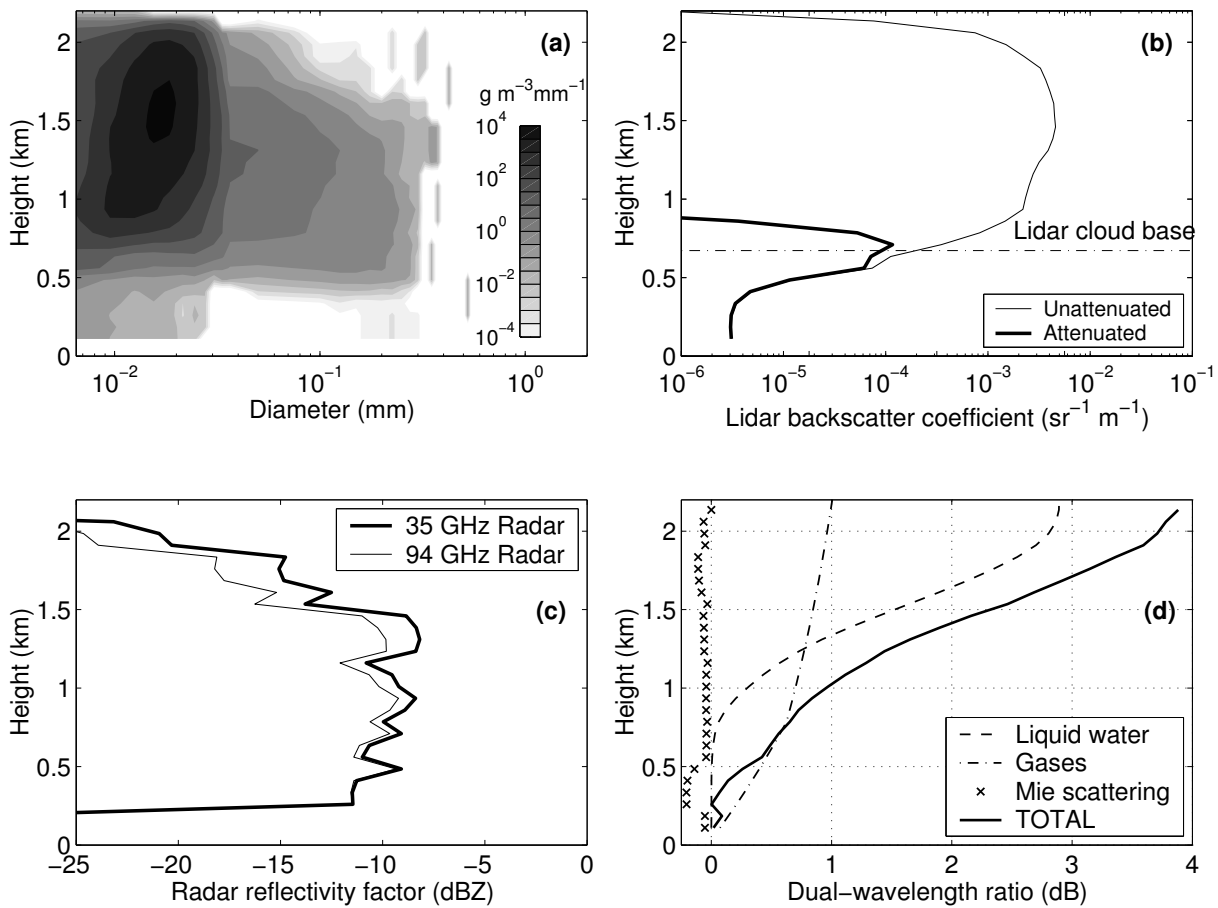

FIG. 3: Aircraft profile through stratocumulus on 12 June 1992 of (a) spectral density of liquid water content versus diameter, (b) simulated attenuated and unattenuated lidar backscatter coefficient, (c) simulated reflectivity factor at $35 \mathrm{GHz}$ and $94 \mathrm{GHz}$, (d) simulated DWR, both for the individual components and the total. 


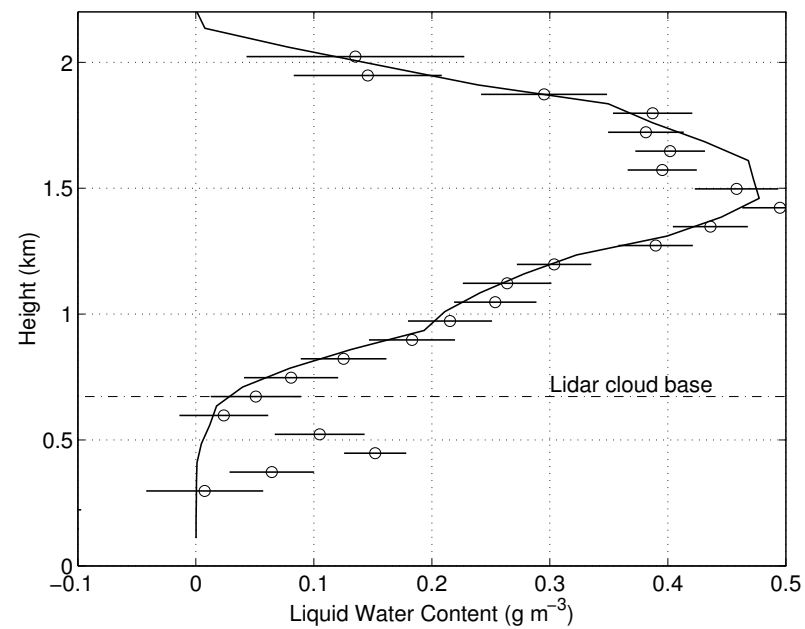

FIG. 4: Profile of LWC (solid line) with the corresponding simulated measurements by ground-based dual-wavelength radar for a 1-minute dwell and 2-gate sliding window averages in the vertical (circles and error bars)

down to $500 \mathrm{~m}$ below cloud base.

The dual-wavelength ratio is depicted in Fig. 3d, together with the individual contributions from liquid water attenuation, gaseous attenuation and Mie scattering. The total differential attenuation by the liquid water is nearly $3 \mathrm{~dB}$, while the attenuation by atmospheric gases is around a third of this. An important point to note is that despite drizzle drops being present through the depth of the cloud, they are predominantly smaller than $400 \mu \mathrm{m}$ and so in the Rayleigh scattering regime. The Mie contribution to DWR is therefore small, falling to only $-0.05 \mathrm{~dB}$ between 1.5 and $2 \mathrm{~km}$ and $-0.2 \mathrm{~dB}$ at cloud base.

Next the dual-wavelength retrieval of LWC was simulated and compared with the true LWC profile. The solid line in Figure 4 depicts the true profile and the error bars show the values that would be obtained by dualwavelength radar for a 1-minute dwell with averaging over 2 gates to give $150 \mathrm{~m}$ vertical resolution. The correction for gaseous attenuation is assumed to be perfect. The error bars were calculated using (7) assuming that both radars have a noise-equivalent reflectivity at $1 \mathrm{~km}$ of $-25 \mathrm{dBZ}$. The larger errors at cloud top are due to low reflectivities at the edge of the cloud, resulting in SNR $<0 \mathrm{~dB}$. At cloud base (i.e. at $700 \mathrm{~m}$ and below), the DWR gradient is affected by Mie scattering of large drizzle drops. The technique wrongly attributes these fluctuations in gradient to liquid water attenuation, with the result that several values of LWC are too high by up to $0.15 \mathrm{~g} \mathrm{~m}^{-3}$. However, these biases appear below lidar cloud base, where only drizzle is present, and so would be rejected in a real retrieval. Biases due to this effect are present between 1.5 and $2 \mathrm{~km}$ but to a lesser extent. It should be noted that the statistical sampling of large driz- zle drops is rather poor from aircraft and so the resulting abrupt changes in the simulated DWR profile may not occur to the same extent in real radar observations.

Comparing Figs. $3 \mathrm{c}$ and 4 it can be seen that the profiles of LWC and $Z$ have a quite different shape, indicating that methods relating LWC to the $Z$ profile (e.g. Frisch et al. 1998) are likely to fail when drizzle is present.

\section{Results}

\section{a. Chilbolton 9 April 1999 case}

We first present retrievals of stratocumulus LWC from dual-wavelength radar measurements at Chilbolton on 9 April 1999. Two radars were operated at vertical, the 35$\mathrm{GHz}$ Rabelais (beamwidth $0.43^{\circ}$ ) and the $94-\mathrm{GHz}$ Galileo (beamwidth $0.5^{\circ}$ ). In order to maximize overlap, the two radars were mounted within a few meters of each other. Figure 5a depicts the $35-\mathrm{GHz}$ reflectivity field between 0800 and 1230 UTC. The temporal resolution is $10 \mathrm{~s}$ and height resolution $60 \mathrm{~m}$. The dashed line represents the cloud base deduced from the backscattered signal of the lidar ceilometer at Chilbolton shown in Fig. 5b. The reflectivity and lidar backscatter fields show a cloud layer characterised by a very flat top and a variable cloud base, typical of stratocumulus (e.g. Price and Wood 2002). According to a radiosonde launched at 10 UTC from Larkhill, $25 \mathrm{~km}$ from Chilbolton, the temperature at cloud top was $6^{\circ} \mathrm{C}$, indicating that the cloud was entirely in the liquid phase.

Reflectivity fields from the $35-\mathrm{GHz}$ and $94-\mathrm{GHz}$ radars were interpolated on to the same $60-\mathrm{m}$ range grid and averaged into 1-minute bins. Figure $5 \mathrm{c}$ shows the corresponding DWR after weak vertical smoothing (equivalent to 2-gate averaging), and as a result of gas and liquid attenuation it increases monotonically with height. The data beneath cloud base have been screened out as the water content will be very low and any retrievals of significant LWC are likely to be the spurious result of Mie scattering effects. At the top of the cloud a few pixels were removed due to low SNR and the consequent large errors in LWC.

The LWC derived from DWR is shown Fig. 5d, with gaseous attenuation calculated and subtracted using the Larkhill radiosonde ascent. A general increase in LWC towards cloud top is apparent, typical of well-mixed stratocumulus. Figure 6a shows the liquid water path (LWP) obtained using the dual-wavelength technique (essentially using cloud-top DWR after correction for gaseous attenuation). Since there was no microwave radiometer data available for this case, we have plotted instead the adiabatic LWP calculated using cloud base and top measured by radar and lidar (although interpolating stratocumulus cloud base where it was obscured by the cumulus present at 0930 UTC below $300 \mathrm{~m}$ ). The agreement is very good, with a mean difference of only $20 \mathrm{~g} \mathrm{~m}^{-2}$ and an rms dif- 

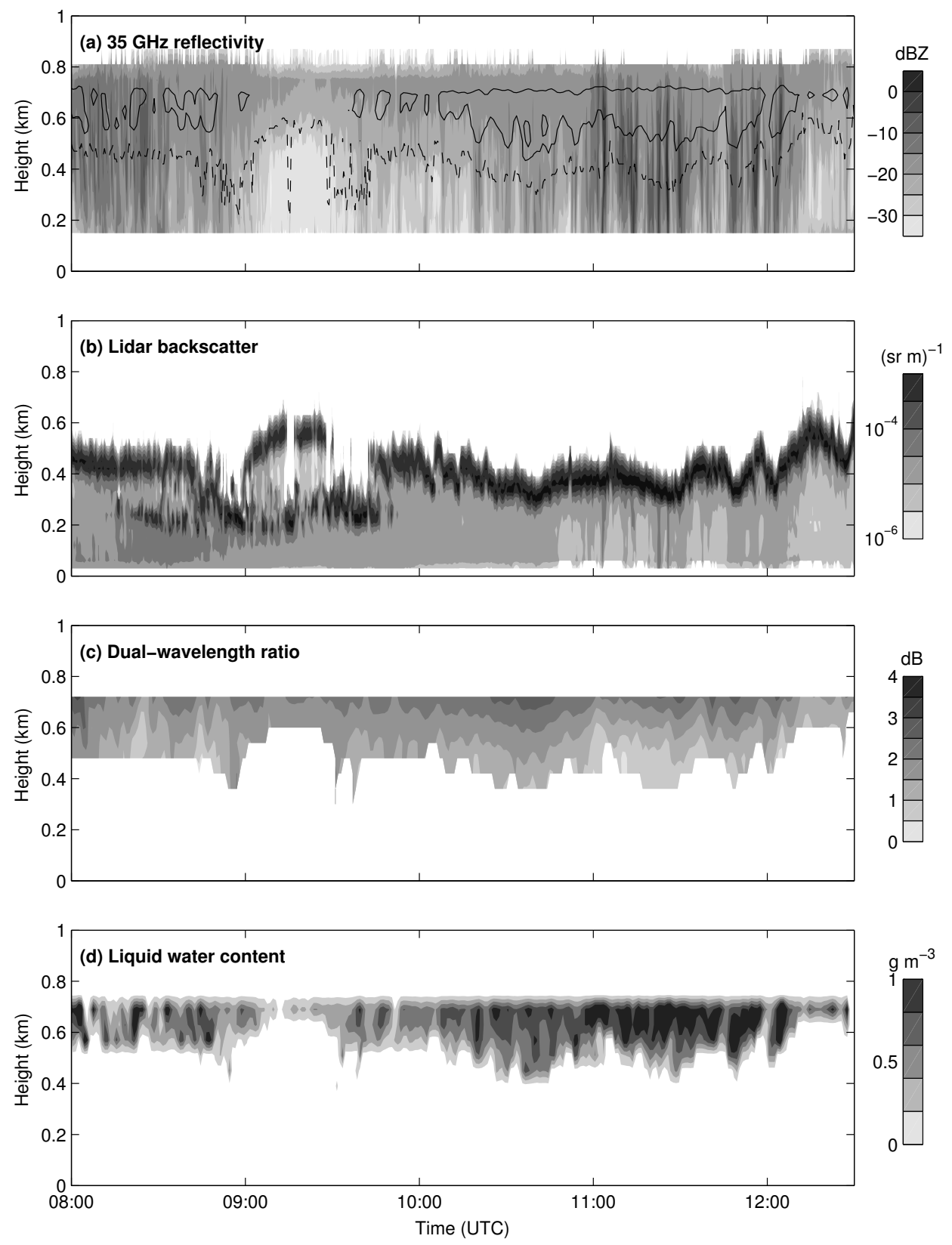

FIG. 5: Dual-wavelength measurements at Chilbolton on 9 April 1999: (a) radar reflectivity factor at $35 \mathrm{GHz}$ with lidar cloud base shown by the dashed line and LWC $=0.6 \mathrm{~g} \mathrm{~m}^{-3}$ by the solid contour, (b) attenuated lidar backscatter coefficient, (c) dual wavelength ratio above cloud base, and (d) liquid water content. The data were averaged to 1 minute in the retrieval of liquid water content.

ference of $50 \mathrm{~g} \mathrm{~m}^{-2}$.

\section{b. Oklahoma 23 September 1997 case}

We now present observations made with the Cloud Profiling Radar System (CPRS) at the Atmospheric Radiation Measurement (ARM) site in Oklahoma. The CPRS is a dual-wavelength Doppler radar at $33 \mathrm{GHz}$ and $95 \mathrm{GHz}$, built on a single feed and single lens an- tenna (Sekelsky and McIntosh 1996). The difference in beamwidth is significant $\left(0.6^{\circ}\right.$ at $35 \mathrm{GHz}$ and $0.2^{\circ}$ at $94 \mathrm{GHz}$ ), but the single aperture eliminates antenna pointing errors and reduces overlap discrepancies.

Figure $7 \mathrm{a}$ depicts the reflectivity field observed at $33 \mathrm{GHz}$ in a deep boundary-layer cloud. The structure is more complex than the Chilbolton case, with the thick cloud below $1.5 \mathrm{~km}\left(13^{\circ} \mathrm{C}\right)$ overlaid by a thinner layer 

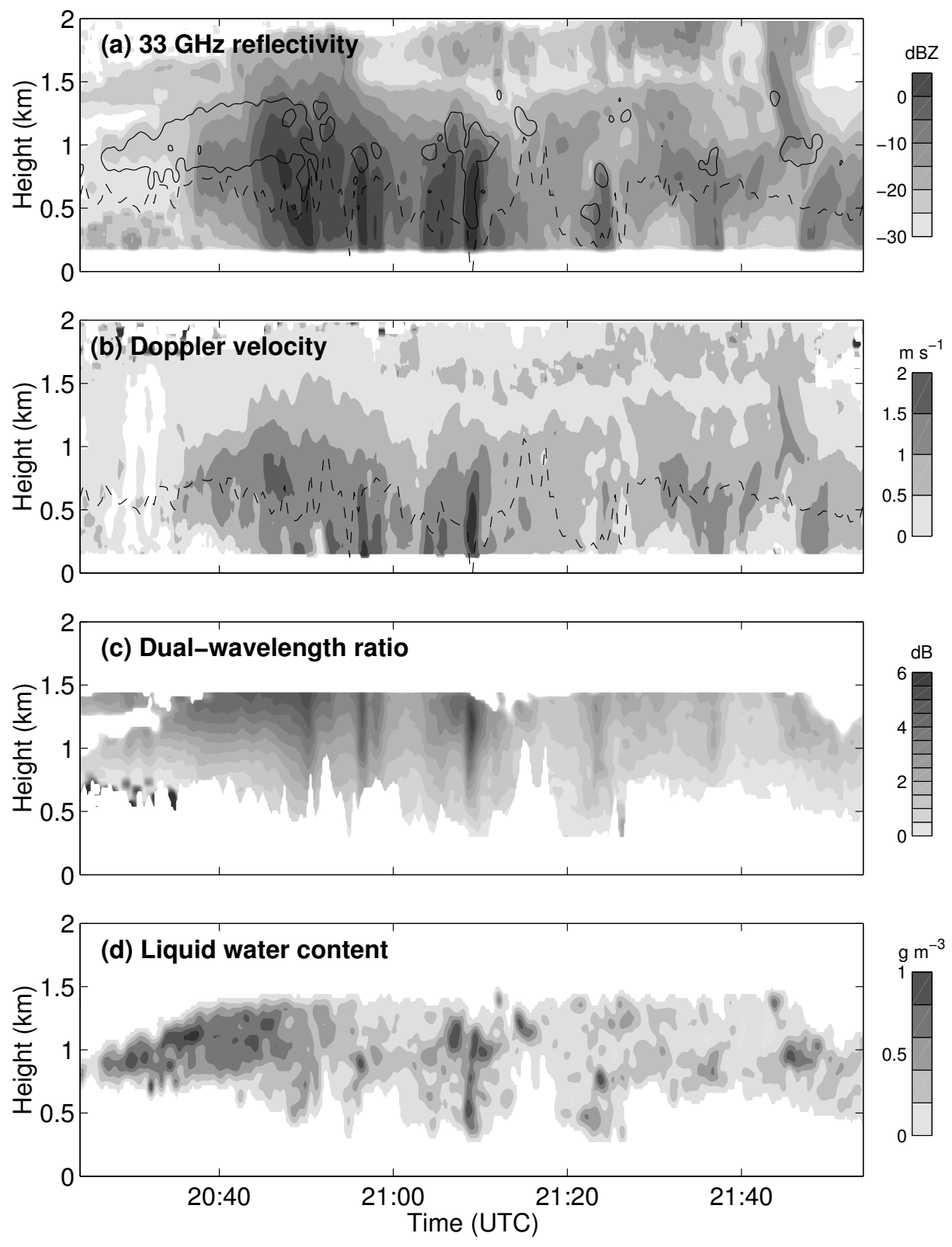

FIG. 7: Dual-wavelength measurements by the CPRS at the ARM facility in Oklahoma on 23 September 1997: (a) radar reflectivity factor at 33 $\mathrm{GHz}$ with ceilometer cloud base and $0.45 \mathrm{~g} \mathrm{~m}^{-3}$ contour of LWC deduced from the dual-wavelength technique, (b) Doppler velocity and ceilometer cloud base, (c) dual-wavelength ratio, and (d) liquid water content. The data were averaged to 1 minute and 2 gates before liquid water content was derived.

with cloud top up to $2.4 \mathrm{~km}\left(9^{\circ} \mathrm{C}\right)$. The $95-\mathrm{GHz}$ radar was less sensitive than the $33-\mathrm{GHz}$ radar, and failed to fully detect the upper layer. The pixels above $1.4 \mathrm{~km}$ were not considered in the retrieval since the SNR was too low. Figure $7 \mathrm{~b}$ depicts mean Doppler velocity and ceilometer cloud base (dashed line); the increase in downwards velocity towards cloud base indicates the presence of drizzle. Since the acquisition is perfectly synchronised no interpolation was required; the data from both channels were simply averaged over 1 minute and $60 \mathrm{~m} \mathrm{(2}$ gates). DWR calculated from the averaged fields is presented in Fig. 7c, with pixels below cloud base and close to cloud top removed in order to eliminate spurious effects due to Mie scattering and low SNR. A more patchy LWC structure than observed in the previous case can be seen in Fig. 7d, suggesting less vigorous overturning. A possible explanation is that infrared radiative cooling from cloud top (an important source of negative buoyancy in boundary layer clouds) at $1.4 \mathrm{~km}$ is impeded by the presence of the layer above. At this site a dual-channel mi- 

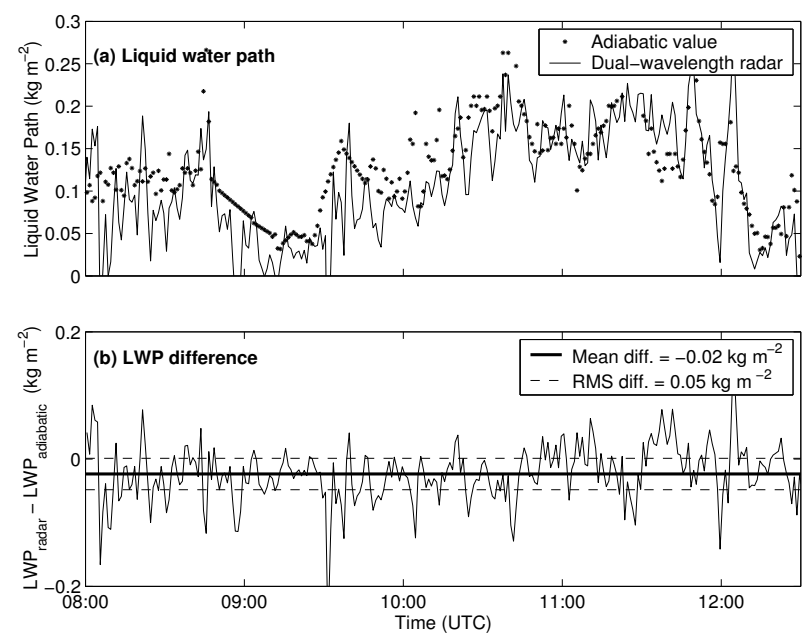

FIG. 6: (a) Liquid water path (LWP) inferred from dual-wavelength radar measurements (solid line) and adiabatic value (dots), and (b) the corresponding difference in LWP.
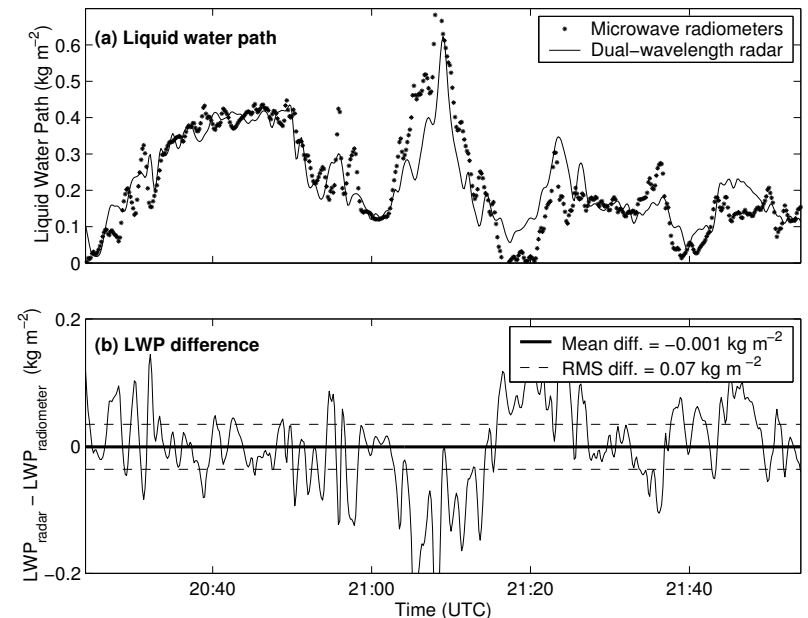

FIG. 8: (a) Liquid water path (LWP) inferred from dual-wavelength radar measurements (solid line) and radiometer measurements (dots), and (b) the corresponding difference in LWP.

crowave radiometer was present operating at $23.8 \mathrm{GHz}$ and $31.4 \mathrm{GHz}$, and Fig. 8a shows a comparison between the LWP estimated from the microwave radiometer measurements (expected absolute accuracy $50 \mathrm{~g} \mathrm{~m}^{-2}$ ) and the dual-wavelength radar technique. It can be seen that the two retrievals match very well in the mean, with the rms difference being $70 \mathrm{~g} \mathrm{~m}^{-2}$. It should be noted that some of the difference may be explained by the fact that the radiometers were located around $250 \mathrm{~m}$ away from the dual-wavelength radar.

\section{Conclusions}

In this paper we have shown that dual-wavelength radar at $35 \mathrm{GHz}$ and $94 \mathrm{GHz}$ has the ability to make accurate vertically-resolved measurements of LWC in boundary-layer clouds. Comparison with microwave radiometer shows good agreement in liquid water path, and in a case of well-mixed stratocumulus the profile was found to be close to adiabatic, on average. The particular strength of the technique is that it does not need to make any assumptions on the nature of the size distribution, with the exception that the drops should be small enough to scatter within the Rayleigh regime at both frequencies. This therefore enables accurate retrieval even in the presence of drizzle, an advantage over many existing radar techniques (e.g. Frisch et al. 1998; Austin and Stephens 2001). When scattering outside the Rayleigh regime does occur at $94 \mathrm{GHz}$, it can be identified from the difference in Doppler velocity measured by the two radars.

It should be noted that the technique is only possible if reflectivity can be estimated to a very high precision (of order $0.03 \mathrm{~dB}$ ). Sufficient precision is unlikely to be achieved by FMCW radars or those that use pulse compression, due to their susceptibility to range sidelobes. Useful measurements can be made at lower frequencies, such as $10 \mathrm{GHz}$ and $35 \mathrm{GHz}$, but the much reduced differential attenuation for a given water content means that retrievals with a high enough vertical resolution to be useful in stratocumulus are not possible. The only means of retrieving the vertical profile of LWC in stratocumulus is to use $35 \mathrm{GHz}$ and $94 \mathrm{GHz}$ radars; for a 1-minute dwell, a high signal-to-noise ratio and averaging over 2 gates, an accuracy of $0.04 \mathrm{~g} \mathrm{~m}^{-3}$ can be achieved.

Acknowledgements. The Galileo radar was developed for the European Space Agency by Officine Galileo, The Rutherford Appleton Laboratory and the University of Reading, under ESTEC Contract 10568/NL/NB. The Rabelais radar was on loan from the University Paul Sabatier in Toulouse. We thank the US Department of Energy as part of the Atmospheric Radiation Measurement Program and University of Massachusetts for the CPRS radar data. We are grateful to Phil Brown for providing the ASTEX aircraft data and the Met Office for the radiosonde data. This research benefited from NERC grants GR3/8765 and NER/T/S/1999/00105.

\section{APPENDIX}

\section{A. The precision of reflectivity measurements}

In this appendix we derive Eq. 6, the expected error on an averaged $Z$ measurement after noise subtraction. The radar is assumed to be of the ordinary pulsed type, utilizing a square-law detector and performing linear averages with no spectral processing.

Suppose that at a particular range gate the average echo power, $\bar{P}$, is calculated by linear averaging of $M$ samples. $\bar{P}$ is the sum of the required meteorological signal, $\bar{S}$, and the background noise, $\bar{N}$ (a combination of instrument noise and thermal emission by the atmosphere). Since 
the probability distribution of $P$ is a simple exponential (Doviak and Zrnić 1993) with a standard deviation equal to the mean, the standard error of $\bar{P}$ is given by

$$
\Delta P=\frac{\bar{P}}{\sqrt{M_{\mathrm{i}}}},
$$

where $M_{\mathrm{i}}$ is the number of equivalent independent samples. If the noise is much larger than the signal then every pulse will be independent, and $M_{\mathrm{i}}=M$, but if the signal is much larger than the noise then $M_{\mathrm{i}}$ is equal to $M_{\mathrm{i}, S}$, the number of independent samples for the signal only. We write $M_{\mathrm{i}, S}=M \tau_{\mathrm{s}} / \tau_{\mathrm{i}}$, where $\tau_{\mathrm{s}}$ is the time between samples and $\tau_{\mathrm{i}}$ is the 'time to independence', i.e. the time it takes for the individual scatterers to move relative to one another on the scale of the wavelength such that the signal is essentially uncorrelated. In the usual case of $M \gg M_{\mathrm{i}, S} \gg 1, \tau_{\mathrm{i}}$ is given by (Atlas 1964)

$$
\tau_{\mathrm{i}}=\frac{\lambda}{4 \pi^{\frac{1}{2}} \sigma_{w}}
$$

where $\lambda$ is the radar wavelength and $\sigma_{w}$ is the spectral width, defined as the standard deviation of the reflectivityweighted droplet vertical velocities in the radar pulse volume.

We now derive $M_{\mathrm{i}}$ from $M$ and $M_{\mathrm{i}, S}$. It was shown by Papoulis (1965) that

$$
\frac{1}{M_{\mathrm{i}}}=\sum_{m=-(M-1)}^{M-1} \frac{M-|m|}{M^{2}} \rho_{\mathrm{r}}\left(m \tau_{\mathrm{s}}\right)
$$

where $\rho_{\mathrm{r}}\left(m \tau_{\mathrm{s}}\right)$ is the normalised autocorrelation between the output samples of the receiver a time $m \tau_{\mathrm{s}}$ apart. For a square-law detector (i.e. one that determines $\bar{P}$ by averaging estimates of the power rather than the amplitude or the logarithm of the power), $\rho_{\mathrm{r}}=\rho_{P}^{2}$, where $\rho_{P}$ is the normalised autocorrelation function of the in-phase $(I)$ or quadrature $(Q)$ components of $P$. The unnormalised autocorrelation at lag $m \tau_{\mathrm{s}}$ is given by (Doviak and Zrnić 1993)

$$
\bar{P} \rho_{P}\left(m \tau_{\mathrm{s}}\right)=\bar{S} \rho_{S}\left(m \tau_{\mathrm{s}}\right)+\bar{N} \rho_{N}\left(m \tau_{\mathrm{s}}\right),
$$

where $\rho_{S}$ and $\rho_{N}$ designate the normalised autocorrelation of the $I$ or $Q$ components of the signal and noise respectively. Since the noise is uncorrelated from one pulse to the next, $\rho_{N}\left(m \tau_{\mathrm{s}}\right)$ is equal to the delta function $\delta_{m}$ where $\delta_{m}$ is 1 for $m=0$ and zero otherwise. Hence

$$
\rho_{r}\left(m \tau_{\mathrm{s}}\right)=\rho_{P}^{2}\left(m \tau_{\mathrm{s}}\right)=\frac{\bar{S}^{2}}{\bar{P}^{2}} \rho_{S}^{2}\left(m \tau_{\mathrm{s}}\right)+\frac{\bar{N}^{2}+2 \bar{S} \bar{N}}{\bar{P}^{2}} \delta_{m} .
$$

It can be seen from (A3) and (A5) that the correct weighting between $M$ and $M_{\mathrm{i}, S}$ to determine $M_{\mathrm{i}}$ is given by

$$
\frac{1}{M_{\mathrm{i}}}=\frac{\bar{S}^{2}}{\bar{P}^{2}} \frac{1}{M_{\mathrm{i}, S}}+\frac{\bar{N}^{2}+2 \bar{S} \bar{N}}{\bar{P}^{2}} \frac{1}{M} .
$$

Finally this is substituted into (A1) to get the error in the measured mean power:

$$
\Delta P=\left(\frac{\bar{S}^{2}}{M_{\mathrm{i}, S}}+\frac{\bar{N}^{2}+2 \bar{S} \bar{N}}{M}\right)^{\frac{1}{2}}
$$

We are interested in obtaining an estimate of the meteorological signal, $\hat{S}$, from which we calculate $Z$. Typically one would make an estimate of the noise level, $\hat{N}$, by averaging the power in cloud-free gates elsewhere in the profile, and subtract it from $\bar{P}$ :

$$
\hat{S}=\bar{P}-\hat{N} ; \quad \Delta \hat{S}^{2}=\Delta P^{2}+\Delta \hat{N}^{2} .
$$

However, as around 50 gates are used in the noise estimate, $\Delta \hat{N}^{2} \ll \Delta P^{2}$, so in fact $\Delta \hat{S} \simeq \Delta P$. In logarithmic units the random error in reflectivity is $\Delta Z_{\mathrm{dB}}=$ $4.343 \Delta \hat{S} / \hat{S}$, and hence from (A7) we have

$$
\Delta Z_{\mathrm{dB}}=4.343\left(\frac{1}{M_{\mathrm{i}, S}}+\frac{1}{M}\left[\frac{1}{\mathrm{SNR}^{2}}+\frac{2}{\mathrm{SNR}}\right]\right)^{\frac{1}{2}} .
$$

where SNR is the linear signal-to-noise ratio, defined as $\bar{S} / \bar{N}$. Substitution of (A2) and introduction of the number of averaged range gates yields (6).

\section{REFERENCES}

Atlas, D., 1954: The estimation of cloud parameters by radar. J. Meteorol., 11, 309-317.

Atlas, D., 1964: Advances in radar meteorology. Advances in Geophys., 10, 318-478.

Austin, R. T., and G. L. Stephens, 2001: Retrieval of stratus cloud microphysical parameters using millimeter-wave radar and visible optical depth in preparation for CloudSat - 1. Algorithm formulation. J. Geophys. Res., 106, 28 233-28 242.

Doviak, R. J., and D. S. Zrnić, 1993: Doppler radar and weather observations. 2nd Ed. Academic Press.

Eccles, P. J., and E. A. Mueller, 1971: X-band attenuation and liquid water content estimation by dual-wavelength radar. J. Appl. Meteorol., 10, 1252-1259.

Fox, N. I., and A. J. Illingworth, 1997: The potential of a spaceborne radar for the detection of stratocumulus clouds. J. Appl. Meteorol., 36, 676-687.

Frisch, A. S., G. Feingold, C. W. Fairall, T. Uttal and J. B. Snider, 1998: On cloud radar and microwave radiometer measurements of stratus cloud liquid water profiles. J. Geophys. Res., 103, 23195 23197.

Gaussiat, N., H. Sauvageot and A. J. Illingworth, 2003: Cloud liquid water and ice content retrieval by multi-wavelength radar. J. Atmos. Oceanic Technol., 20, 1264-1275.

Gosset, M., and H. Sauvageot, 1992: A dual-wavelength radar method for ice-water characterization in mixed-phase clouds. J. Atmos. Oceanic Technol., 9, 538-547.

Ichimura, U., W. Fujiwara and T. Yanase, 1980: The size distribution of cloud drops measured in small maritime cumulus clouds. J. Meteorol. Soc. Jpn., 58, 403-415.

Liebe, H. J., 1985: An updated model for millimeter-wave propagation in moist air. Radio Science, 20, 1069-1089.

Liebe, H. J., T. Manabe and G. A. Hufford, 1989: Millimeter-wave attenuation and delay rates due to fog/cloud conditions. IEEE AP, 37, 1617-1623. 
Martner, B. E., R. A. Kropfli, L. E. Ash and J. B. Snider, 1993: Dualwavelength differential attenuation radar measurements of cloud liquid water content. Proc. 26th AMS Conf. on Radar Meteorol., Norman, Oklahoma.

Miles, N. L., J. Verlinde and E. E. Clothiaux, 2000: Cloud droplet size distributions in low-level stratiform clouds. J. Atmos. Sci., 57, 295311.

Papoulis, A., 1965: Probability, random variables, and stochastic processes. McGraw-Hill, New York.

Pinnick, R. G., S. G. Jennings, P. Chýlek, C. Ham and W. T. Grandy, 1983: Backscatter and extinction in water clouds. Geophys. Res. Lett., 25, 6787-6796.

Price, J. D., and R. Wood, 2002: Comparison of probability density functions for total specific humidity and saturation deficit humidity, and consequences for cloud parametrization. Quart. J. Roy. Meteorol. Soc., 128, 2059-2072.

Randall, D. A., J. A. Coakley Jr., C. W. Fairall, R. A. Kropfli and D. H. Lenshow, 1984: Outlook for research on sub-tropical marine stratiform clouds. Bull. Am. Meteorol. Soc., 65, 1290-1301.

Sekelsky S. M., and R. E. McIntosh, 1996: Cloud observations with a polarimetric $33 \mathrm{GHz}$ and $95 \mathrm{GHz}$ radar. Meteorol. Atmos. Phys., 59, 123-140.

Slingo, A., 1990: Sensitivity of the earth's radiation budget to changes in low clouds. Nature, $\mathbf{3 4 3}, 49-51$.

van de Hulst, H. D., 1957: Light scattering by small particles. Wiley and sons, $470 \mathrm{pp}$.

Vivekanandan, J., B. E. Martner, M. K. Politovich and G. Zhang, 1999: Retrieval of atmospheric liquid and ice characteristics using dualwavelength radar observations. IEEE Trans. on Geoscience and Remote Sensing, 37, 2325-2334.

Vivekanandan, J., G. Zhang and M. K. Politovich, 2001: An assessment of droplet size and liquid water content derived from dualwavelength radar measurements to the application of aircraft icing detection. J. Atmos. Oceanic Technol., 18, 1787-1798.

Wood, R., 2000: Parametrization of the effect of drizzle upon the droplet effective radius in stratocumulus clouds. Quart. J. Roy. Meteorol. Soc., 126, 3309-3324. 